\title{
Public health in the Canadian Arctic: contributions from International Polar Year research
}

\author{
Sandra Owens • Philippe De Wals • Grace Egeland • \\ Christopher Furgal • Yang Mao • Gerald Y. Minuk • \\ Paul A. Peters • Manon Simard • Éric Dewailly
}

Received: 10 April 2012 / Accepted: 29 July 2012

(C) The Author(s) 2012. This article is published with open access at Springerlink.com

\begin{abstract}
The contributions of several IPY health projects are highlighted in the context of population health indicators for Inuit Nunangat. Food and housing are two critical social determinants of health contributing to health issues on many levels. The nutritional deficit associated with food insecurity and the transition away from traditional and towards market foods represents a dual risk with profound consequences. Knowledge of the physiological benefits associated with traditional food consumption is increasing, including for mental health and chronic disease. Ensuring the safety of traditional foods in terms of zoonotic diseases is thus highly valuable and efforts to institute adequate monitoring and address
\end{abstract}

Electronic supplementary material The online version of this article (doi:10.1007/s10584-012-0569-3) contains supplementary material, which is available to authorized users.

S. Owens $(\bowtie) \cdot$ É. Dewailly

Axe santé des populations et environnementale, Centre de recherche du Centre hospitalier universitaire de Québec, Quebec, Canada

e-mail: sandra.owens@crchul.ulaval.ca

P. De Wals

Département de médecine sociale et préventive, Université Laval, Quebec, Canada

G. Egeland

Centre for Indigenous Peoples' Nutrition and Environment (CINE) and School of Dietetics and Human Nutrition, Macdonald Campus, McGill University, Montreal, Canada

C. Furgal

Departments of Indigenous Studies and Environment and Resource Studies/Science, Gzowski College Trent University, Peterborough, Canada

Y. Mao

Centre for Chronic Disease Prevention and Control, Public Health Agency of Canada, Ottawa, Canada

G. Y. Minuk

Department of Internal Medicine, University of Manitoba, Winnipeg, Canada

P. A. Peters

Health Analysis Division, Statistics Canada, Ottawa, Canada

M. Simard

Nunavik Research Center, Makivik Corporation, Nunavik, Canada 
knowledge gaps are underway. Acute respiratory disease among the young remains a significant public health issue with potential long term effects. The human papilloma virus is manifesting itself among women across northern Canada with high risk types that are more similar to profiles observed in Europe than in North America with possible implications for immunization programs. Despite a high prevalence of Hepatitis B virus infections among residents of Inuit Nunangat, the outcomes appear to be relatively benign. Communication of new knowledge on the manifestation of this virus among northern populations is provided to health care providers in the North through modern technology.

\section{Introduction}

For the first time in the history of the International Polar Year (IPY), people and communities in the North figure prominently among those components of the polar system receiving attention in Canada (Aboriginal Affairs and and Northern Development Canada 2011; Parkinson 2008). In fact, the health of peoples inhabiting the North has increasingly drawn attention over recent history. Supporting this knowledge development are the major funding agencies which have identified health in the Canadian northern context as priority (e.g. Northern Contaminants Program, the Nasivvik Centre for Inuit Health and Changing Environments, ArcticNet and now the IPY).

While the people of Inuit Nunangat (Fig. 1) fare better than many populations on a global scale, compared to fellow Canadians they endure a health status that is unnecessarily compromised. In other words, they are subject to health inequality. There are key factors

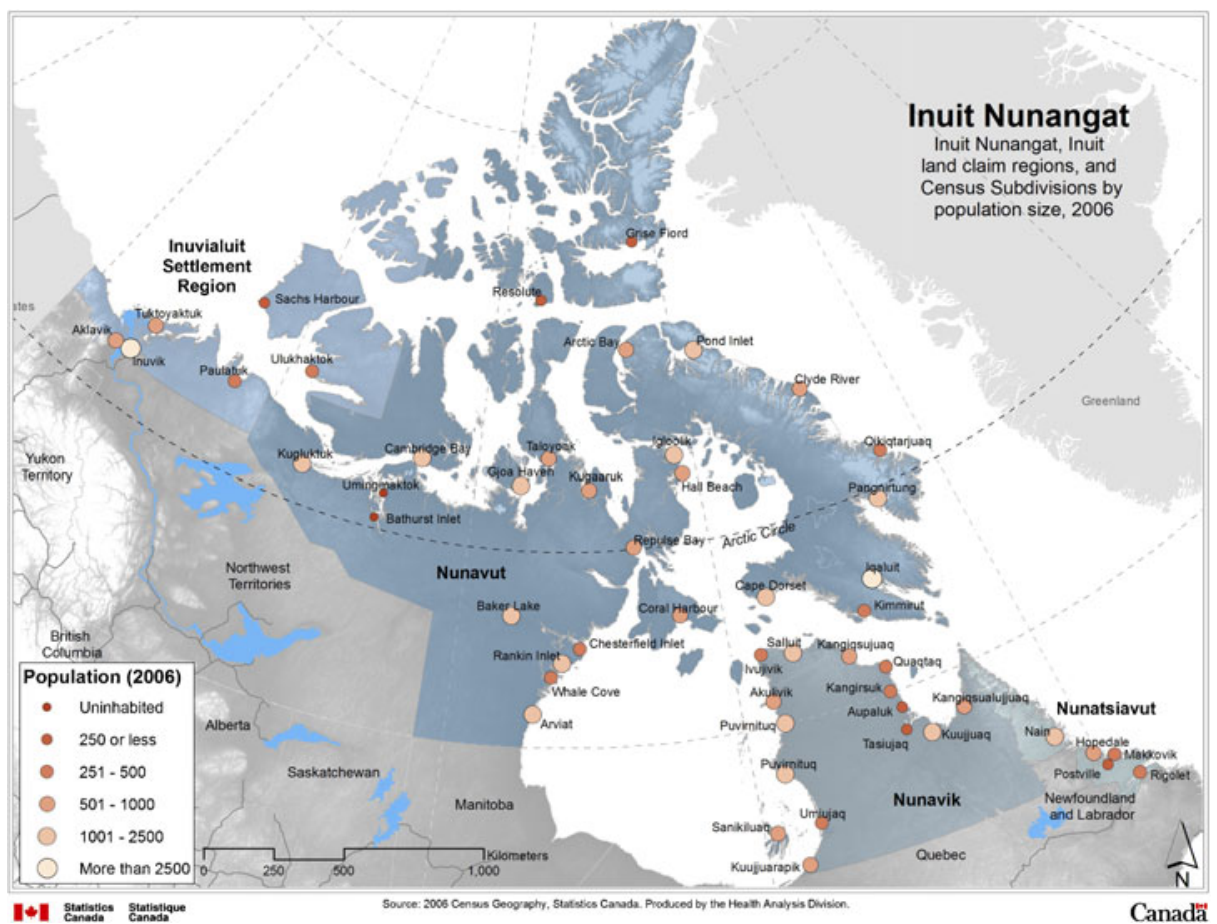

Fig. 1 Map of the Inuit Regions of Canada 
to consider in understanding individual and community health among Arctic populations today. Inuit have experienced rapid change from a semi-nomadic lifestyle a little more than half a century ago, to being settled and connected to the rest of the world today (Inuit Tapiriit Kanatami 2011). In addition, despite their relative isolation from most industrial point sources of pollution, indigenous traditional ways of life entail an intimate proximity to their environment with all that is beneficial, such as nutrients in marine fat, as well as all that is deleterious such as with mercury contamination from the same animals. Finally, although not of least importance, the demographics of Indigenous populations in northern Canada are very significant on many levels. With the youngest population in Canada, Inuit children and infants represent a sizable population susceptible to the effects of any inadequacy in what determines individual and community health outcomes. Science taking place on, with and by northern inhabitants also represents an opportunity to overcome the many challenges and promote positive human health outcomes.

This paper presents the context, justification, results and interpretations to date of the several Canadian IPY human health projects. While the full impact of these research projects will unfold over the next few months and years, there is new knowledge to be accessed and messages to be distilled from the research to inform public health and policies. These IPY health projects wrap around three major themes: dietary transition and the emergence of chronic disease (the Inuit Health Survey); good and bad fats with the Urqsuk program; and infectious diseases.

Additional detail on Peoples of the North can be found in Supplemental Electronic Material 1. This information reviews the geography of inhabitants of Northern Canada using the various lenses adopted by the research teams, as well as a selection of critical population health indicator data over time.

\section{Dietary transition and emergence of chronic disease: the IPY component of the International Inuit Cohort}

The Circumpolar Inuit continue to undergo rapid transitions that are affecting all dimensions of life with implications for emerging changes in the pattern of disease burden (Bersamin et al. 2008; Bjerregaard et al. 2004; Dewailly et al. 2001; Kuhnlein et al. 2004). Moreover, it is recognised that there are critical gaps in data collected for the accurate assessment of health status among Inuit, including children, within Canada (Health Council of Canada 2011). Thus, the IPY Inuit Health Survey was conducted to assess the current health status of Inuit, in a uniform manner, across the Canadian Arctic. The IPY-funded activities involved two distinct research activities led by McGill University's Centre for Indigenous Peoples' Nutrition and Environment (CINE): a health survey of preschoolers residing in Nunavut and the Inuit Health Survey of adults in three out of four Inuit land claim jurisdictions in the Canadian Inuit Nunangat (Inuvialuit Settlement Region (ISR), Nunavut and Nunatsiavut). For the adult IPY Inuit Health Survey, as much as possible, the research methodology and questionnaires were developed to be similar to the Greenlandic ${ }^{1}$ and the Nunavik Inuit Health Surveys. ${ }^{2}$ Their similarity will increase our ability to draw comparisons and to conduct the International Inuit Cohort study which aims to evaluate the determinants of emerging chronic diseases over time in a population undergoing rapid changes in all facets of life. With baseline survey work completed in Canada (Anctil 2008), Greenland (Bjerregaard 2011), and a loosely affiliated project in Alaska (Howard et al. 2005), comparative analyses of

\footnotetext{
${ }^{1}$ See http://circumpolarcohort.crchuq.ca/Greenland.html

${ }^{2}$ See http://circumpolarcohort.crchuq.ca/Nunavik_html
} 
cardiovascular disease risk factors is now in the planning phase. Thus, the highlights of research findings emerging from the IPY Inuit Health Survey are presented.

\section{Box 1 International Inuit Cohort Study}

With its thousands of participants, the International Inuit Cohort Study is the largest health study
of Circumpolar Inuit and as such represents a unique resource of immense potential for research -
and therefore intervention. Participants and communities have received a wealth of information
and knowledge about their health status and several peer reviewed scientific publications have
contributed to the state of knowledge. The true strength of a cohort is in following it over time,
allowing the identification of trends.
The Study is based on three health surveys conducted in Canada and Greenland between 2004 and
2010 . Chronologically, the first survey was conducted in Nunavik in 2004. The second took place
over a period of 4 years on the entire territory of Greenland (2004-2010). Finally, conducted in
2007 and 2008 , the (IPY) Inuit Health Survey covers a vast area including Nunavut, Nunatsiavut
and Inuvialuit.

\section{The IPY Inuit Health Survey for adults}

\subsection{Survey methodology}

In brief, a cross-sectional International Polar Year Inuit Health Survey was conducted in the summer and fall 2007 and 2008 by Canadian Coastguard Ship (CCGS) Amundsen for 33 coastal and by land teams for 3 non-coastal communities: all communities in Inuvialuit Settlement Region (ISR, Northwest Territories), Nunavut, and Nunatsiavut (Northern Labrador) were included. The survey recruited randomly selected households from each community and individuals from within households. A total of 2796 Inuit households were approached, 1901 households participated $(68 \%)$ with a total of 2595 participants. The community sample size average was 54 participants $(25 \%$ ile $=42,75 \%$ ile $=102)$. Research licenses were obtained from the territories and a certificate of Ethical acceptability was issued by the McGill Faculty of Medicine Institutional Review Board. Trained bilingual (English and Inuit dialects) interviewers administered questionnaires and nurses obtained medical histories and current medication usage, took anthropometric measures, collected fasting venous blood samples and administered a 2-h $75 \mathrm{~g}$ oral glucose tolerance test (OGTT). An OGTT was conducted for approximately a third of the study participants who were examined in the morning. Nurses conducted early morning home visits to collect fasting blood samples for participants scheduled later in the day. As the CCGS Amundsen had been refurbished into a research vessel as part of the Centres for Excellence, ArcticNet, research labs and $-80^{\circ}$ freezers were in place to process and store the samples until shipped to CINE, McGill University for storage and analyses.

\subsection{Selected research results to date}

Food security is a condition where communities have safe, culturally acceptable and a nutritionally adequate diet. Inuit experience the highest documented prevalence of food insecurity for Indigenous Peoples in North America based upon our IPY research findings. 
In the IPY Inuit Health Survey, food insecurity, was identified in $62.6 \%$ of Inuit households (95\% confidence interval (CI) 60.3-64.9\%), and 27.2\% (95\% CI 25.1-29.3\%) of households were severely food insecure (Huet et al. 2012). Regional differences were identified in the prevalence of food insecurity which was highest in Nunavut $(68.8 \%)$ compared to ISR (43.3 \%) and Nunatsiavut Region (45.7 \%) (Rosol et al. 2011). However, all three regions had an alarming prevalence of food insecurity. Other regional differences were observed in indicators of poverty. For example, the IPY Inuit Health Survey identified that approximately $20 \%$ of homes in Nunavut and ISR provided shelter to the homeless compared to $11.6 \%$ in Nunatsiavut (Minich et al. 2011). The prevalence of public housing and household crowding also varied by region, with Nunavut having statistically significantly higher prevalence of crowding (29.7 \%) than Nunatsiavut (11.6\%) and ISR (11.6\%) (Minich et al. 2011). Food insecurity was associated with significantly lower healthy eating index scores with lower consumption of vegetables and fruit, grains, dairy products and a greater energy from high-sugar foods when compared to food secure (Huet et al. 2012). Further, we identified a dual burden of food insecurity coupled with dietary transition away from traditional food for nutrient intakes and for biomarkers of nutritional status (Egeland et al. 2011b). For example, we observed a higher trans-fatty acid level as measured in blood cells among the food insecure relative to the food secure, which would have implications for elevating LDLcholesterol and coronary heart disease risk (Sun et al. 2007; Willett 2006). Lower fiber intake was also observed among the food insecure which would have implications for risk of insulin resistance and type 2 diabetes mellitus (DM) (Johnston et al. 2010; Sun et al. 2010). Over the long-term, the range of the diverse dietary differences observed when traditional food was not consumed and when individuals were food insecure would, at least theoretically, elevate risk of chronic diseases in the Arctic. Food insecurity has been related to poorer health and, in particular, type 2 DM in other study populations (Holben and Pheley 2006; Seligman et al. 2007, 2010; Vozoris and Tarasuk 2003). Thus, we are currently evaluating food insecurity for its association with clinical risk factors and pre-existing diagnoses in the IPY Inuit Health Survey.

The suboptimal dietary exposures coincide with a high prevalence of obesity (35\%) and central fat patterning (43.8\%) which may reflect the greater availability and affordability of cheaper energy-dense but nutrient poor foods in the northern communities where food prices are generally twice that of southern cities (Indian and Northern Affairs Canada 2009). While women had a 2-fold greater risk of central fat patterning relative to men, only a subset of women with central fat patterning had elevated triglyceride levels $(\geq 1.7 \mathrm{mmol} / \mathrm{L})$ (Egeland et al. 2011a, b). As such, there were no sex differences observed in the "hypertriglyceridemicwaist" phenotype (i.e., the presence of both an at-risk waist circumference and an elevated triglyceride level). This phenotype has been proposed as a proxy indicator of the presence of visceral fat which is considered more deleterious than subcutaneous fat (Lemieux et al. 2007). This proxy indicator represents a simple but sufficient construct for identifying people at risk for obesity-related complications.

The prevalence of diabetes was similar across regions with an overall prevalence of $5.1 \%$ which is slightly higher than the prevalence of $3 \%$ observed in the Nunavik Inuit Health Survey conducted in 2004 (Chateau-Degat et al. 2010). However, striking regional differences were observed in the prevalence of the hypertriglyceridemic-waist phenotype with the highest prevalence observed in the Inuvialuit Settlement Region (Egeland et al. 2011a, b) which suggests that this region will be at greatest risk for emerging cardiovascular disease and type 2 DM (Lemieux et al. 2007; Kahn and Valdez 2003). Differences in dietary behaviors including traditional food reliance may contribute to the differences observed in the prevalence of the hypertriglyceridemic-waist phenotype. We did note, for example, striking regional differences in red blood cell long-chain n-3 fatty acid status in the survey 
(Zhou et al. 2011) and this and other dietary and lifestyle differences may contribute to the disparate prevalence of this important risk factor.

As expected, the risk of diabetes increased with age in the IPY Inuit Health Survey: diabetes was identified in $12.2 \%$ of Inuit 50 years and older in contrast to only $1.9 \%$ among those under age of 50 years (Egeland et al. 2011a, b). Furthermore, those with both an elevated waist circumference and elevated triglyceride level were at greatest risk for diabetes $(\mathrm{OR}=8.6)$ in analyses adjusted for sex, age, region, education, family history of diabetes, and lipid-lowering medications (Egeland et al. 2011a, b).

Former studies have suggested that Inuit were protected, to some degree, from the metabolic effects of obesity when compared to Caucasian or First Nations populations (Chateau-Degat et al. 2008; Jørgensen et al. 2003; Young et al. 2007). However, the IPY Inuit Health Survey results clearly suggest that any protection associated with Inuit status has been lost as the diabetes prevalence among Canadian Inuit now approaches that of the general Canadian population (Egeland et al. 2011a, b). In Alaska and Greenland, the prevalence of type 2 DM, which was rare in early studies (Mouratoff et al. 1967; Sagild et al. 1966), is now comparable to or exceeding that of predominately Caucasian comparison populations (Ebbesson et al. 1998; Jørgensen et al. 2002; Murphy et al. 1992).

\subsection{Significance of research}

The results emerging from the IPY Inuit Health Survey for adults reveal that considerable work is needed to reduce disparities in the basic necessities required for population health: adequate housing and food security. Further, the transition away from traditional food in the context of food insecurity could have a profound impact upon dietary quality with consequences for nutritional health and well-being and the emergence of diet-related chronic diseases. The results indicate that Inuit status alone is not sufficient to protect against the emergence of chronic disease and that the Inuvialuit Settlement Region is at greatest risk in the Canadian Arctic. Further work in identifying population attributable risks and preventable fractions associated with key risk factors will help in informing policy makers and funding agencies regarding the highest impact risk factors that should be targeted for interventions. While striking epidemiological transitions have occurred in other Indigenous Peoples, the hope for the Arctic is that it is not too late to utilize the IPY study findings to help inform and motivate individuals, communities and public health agencies to launch efforts to prevent the emergence of an epidemic in diet and obesity-related health outcomes.

\section{Nunavut Inuit Child Health Survey}

Life-time disparities in health can begin early in life and given the lack of information on the health status and living conditions of Inuit preschoolers, a Nunavut Inuit Child Health Survey was developed (Egeland et al. 2010a). It was hoped that this survey would add valuable context for understanding trends in dietary transition and emerging obesity and other key health determinants in the population by evaluating these factors among society's most vulnerable, children under 5 years of age.

Therefore, the survey was designed to evaluate a number of health determinants ranging from nutrition (growth, biomarkers of nutritional status, dietary intake, food security), dental health, respiratory health histories and symptoms, injuries, prenatal and early-life exposures (maternal smoking and alcohol consumption, and breastfeeding); home environment (crowding, passive smoking, traditional food sharing networks, type of housing, and state 
of housing), and mercury exposures. Further, as factors associated with "indigeneity" feature prominently as a dimension related to population health, the survey assessed primary language spoken, participation in traditional food sharing networks, presence of an active hunter in the home, among other attributes.

\subsection{Survey methodology}

In brief, the cross-sectional health survey was conducted in the late summer and fall of 2007 and 2008. Territorial research license and McGill Ethics certificate was obtained. A total of 537 households with Inuit 3-5 year olds were successfully contacted, of whom 75 refused and an additional 74 cancelled, resulting in 388 participants and a participation rate of $72.3 \%$. The 388 children represent $26 \%$ of all $3-5$ year old Inuit children in the 16 communities, and the 16 communities represent $76.4 \%$ of the Nunavut 3-5 year old population. The 16 communities were selected based upon achieving representation in terms of community size, latitude, region, and based upon the logistical feasibility of airline routes. Further, certain communities were not included due to their very small number of ageappropriate children relative to costs and flight schedule constraints (Egeland et al. 2010a). Based upon Aboriginal Affairs and Northern Developments' community well-being scores which included labour force activity, education, income, and housing information collected through Statistics Canada's 2006 Census, the 16 selected communities had a community well-being score that was statistically similar to the 9 non-selected communities (JohnsonDown and Egeland 2010). Detailed research methodologies of the Nunavut Inuit Child Health Survey have been published (Egeland et al. 2010a, b).

\subsection{Results}

The Nunavut Inuit Child health survey results have been presented in a plain language DVD and in a non-technical results booklet sent to communities and other stakeholders. In addition, several manuscripts have been published. Key among the findings were that a high prevalence of food insecurity was identified with $69.6 \%$ of Inuit Nunavut households with a 3-5 year olds identified as food insecure and $56 \%$ of households as child-food insecure in 2007-2008 (Egeland et al. 2010b). Child food insecurity was calculated based on responses to the 8 of the 18 -item survey module which pertained specifically to the children in the household (Egeland et al. 2010b). The household and child food insecurity prevalence observed in Nunavut homes with preschoolers was over 7-fold and 10-fold higher, respectively, than that observed for households participating in the Canadian Community Health Survey (Cycle 2.2) of which 9.2\% were household food insecure and $5.2 \%$ were child food insecure. Further, preschoolers from child food insecure homes consumed a greater amount of sugar beverages, less milk and had lower Healthy Eating Index scores when compared to children from child food secure homes (Egeland et al. 2011a, b). A high degree of high-sugar beverage consumption was identified while traditional food consumption represented only $8 \%$ of total energy intake among the $46 \%$ of the children consuming traditional food in the past-day (Johnson-Down and Egeland 2010). Even the low-level of traditional food intake, however, contributed significantly to macro and micronutrient intakes. Further, with $99 \%$ of the children consuming iron-rich traditional food in the past-month, a low prevalence of iron deficiency and iron deficiency anemia was identified among the preschoolers (Pacey et al. 2011). However, while traditional food contributed to vitamin D intake (Johnson-Down and Egeland 2010), traditional food intake and milk consumption (which was low) were insufficient to protect the 
preschoolers against a high prevalence (78.6\%) of vitamin D insufficiency (as assessed by serum $25(\mathrm{OH})<75 \mathrm{nmol} / \mathrm{L}$ ) (El Hayek et al. 2010).

A high prevalence of overweight $(50.8 \%$ ) was identified among the preschoolers who were of average stature for age and sex (Galloway et al. 2010). Galloway et al. (2010) also report that overweight prevalence is increasing in comparison with previous studies. The only dietary correlate of overweight status identified in the survey population, however, was dietary fiber which was significantly lower among overweight than normal-weight preschoolers after adjustment for total energy intake (Johnson-Down and Egeland 2010). A high prevalence of parental-reported dental caries was noted $(69 \%)$ where children consuming vitamin D, calcium or fluoride supplements, and milk had a lower risk while those consuming high amounts of sugar had a higher risk of parental-reported carries (Pacey et al. 2010). The findings add to the emerging evidence that milk and its combined or individual constituents, such as vitamin D and casein phosphopeptides (which have beneficial effects on bone mineralization and remineralization) may protect against dental carries (Ferrazzano et al. 2008; Zhang et al. 2009).

Inuit infants are at high risk for respiratory infections and thus a respiratory health component was added to the survey. In a preliminary descriptive paper of the respiratory signs and symptoms of the preschoolers, severe lower respiratory tract infections in the first 2 years of life was associated with a higher prevalence of respiratory morbidity among the 35 year olds (Kovesi et al. 2011).

\subsection{Significance of research to date}

The Nunavut Inuit Child Health Survey has been highly successful. The findings of the child health survey has resulted in a Nunavut food security task force, a federal call for proposals for early-age obesity intervention/prevention, and territorial nutritionists indicate that the findings (which are shared with them in a timely and prepublished format) are being heavily relied upon for public health decision making and in setting priorities for nutritional health interventions. From a population health perspective, the preschooler survey identified nutritional characteristics which, if persisting throughout life would theoretically result in greater risk of obesity and diet-related chronic diseases. The results indicate the importance of early life interventions and health promotion strategies to protect Inuit Health and to prevent an epidemiologic transition toward greater chronic disease risk.

\section{Good and bad fats: the Urqsuk program}

Current research is showing that, in terms of health, the total amount of fat in the diet, within an acceptable range, is not as important as the presence of specific fats in the diet as well as the relative amounts, or ratios, of specific fats in the diet. Many of the replacement foods are laden with saturated and trans-fats which offer stability and long shelf lives to market foods. Trans-fats or trans-fatty acids (TFA) originate mainly from commercially hydrogenated vegetable oils, as well as from dairy and meat fats. They are associated with increased risk of cardiovascular disease and certain cancers. (Counil et al. 2011; 2012). In addition, the balance of fats has changed dramatically over the past century. The modern diet typically reflects consumption of excess amounts of n- 6 fatty acid, which is found in high levels in many of the oil seed crops. Because of the rapid societal transition subsequent to the improvement of communication and transportation with southern regions, and with the 
settlement of Inuit populations into permanent communities, a shift away from the traditional lifestyle and diet has taken root in Inuit society (Nobmann et al. 1992; Pars et al. 2001).

The research program seeks to better understand the significance of fats and lipids in Inuit society; to assess the role of long chain polyunsaturated fatty acids (LCPUFAs) on cardiac variability; to test associations between LCPUFA, trans-fatty acids and atherosclerosis; and to see if LCPUFA could play a role in the prevention of psychological distress and suicide. It will help to inform stakeholders at various levels on how to translate the knowledge gained from the program into health related recommendations at the community level. The Urqsuk program is an example of what health survey data can enable by fully exploring the potential of the data collected. Urqsuk analyses data from the 2004 health survey in Nunavik commonly referred to as Qanuippitaa? How are we? $?^{3}$, and is augmented with new field work in Nunatsiavut, Nunavik and Nunavut addressing Inuit perceptions and perspectives around fats.

\section{Community knowledge, perspectives and observations of fats and health}

In 2010 the communities of Nain, Nunatsiavut and Clyde River, Nunavut participated in a study involving focus groups and the administration of questionnaires to gather information about their perceptions around traditional and market fats including observations pertaining to changes in animals over time.

It was found that the vast majority of respondents agreed that traditional or wild food fats are healthier than fats found in store foods. However, the majority of respondents indicated that younger people are eating less traditional food fats, and more store food fats and almost half reported eating less traditional food fats today than they did in the past.

Participants spoke of taking steps to reduce fats in their diet but particularly from market as opposed to traditional foods, and this was mentioned more often among participants over 30 years of age. Only $20 \%$ of Nain participants expressed being concerned about fat in their diet, and this concern was often associated with health risks and with weight gain. Fifty-five percent of respondents believed they need to learn more about fat in their diet and they would like to get that information from Elders, parents, and from nurses or healthcare workers. In Clyde River, $76 \%$ of all survey respondents felt they needed to learn more about fat.

In both communities access to store food fats was deemed to be easy, while access to traditional food fats appear to be easier for Clyde River respondents than for those from Nain. The availability of traditional foods, including the effect of hunting quotas where applicable, directly influences the amount of wild fats consumed. The costs of hunting and lack of transportation for hunting make access more difficult. Craving and eating wild fats were reported as making people feel good, and the belief of the health benefits associated with traditional fats, are factors which motivate people to consume traditional fats. For market foods, the perceived poor quality, high costs and poor selection of healthy store foods may limit the consumption of store food fats. With respect to market food fats, the most popular factors which influence the amount consumed are their affordability, availability, knowledge on how to prepare them and craving them. Hunters and other experts are observing changes in fat composition and amount in key Arctic traditional food species. These changes have been taking place over a long period of time and are associated with environmental change. In Nunatsiavut, caribou fat has changed the most out of all wild food

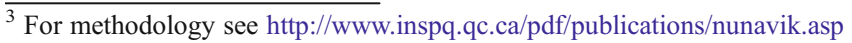


fats. Changes in wild food fats that were noticed by most respondents were changes in texture, thickness, and the amount of fat found in an animal.

Participants from Clyde River discussed changes they have observed in traditional food fats. Of all animals, polar bear was observed as changing the most. Changes in traditional food fats that were noticed by the most people were changes in texture (harder), in taste (different), and in the amount or thickness of fat (less). For both communities involved in the project, it is apparent that the value of traditional food fats for Inuit health is well known and recognized throughout the population. However, there have been changes over time that has resulted in a reduction in the amount of country foods consumed among younger generations and therefore a reduction in the consumption of traditional fats. Having traditional food fats available in the home and being exposed to them starting from a young age; being able to afford to hunt; and having access to transportation to hunt were major factors identified that determine how much fats from the land and sea someone consumes. Variable climatic and environmental conditions exacerbate this issue because of increased risks when traveling on the land to hunt traditional food species. Furthermore, both communities have observed changes in traditional food fats, though the types of animal fats reported and changes in them were different between the two locations.

Both communities have indicated a need and desire for further education and programming on dietary fats and have identified the most appropriate avenues in the communities through which to deliver this. The information gathered in this study can support health professionals when constructing health promotion materials and activities focused on dietary habits. The knowledge gained from hunters and other Inuit experts in the communities can also support wildlife professionals in monitoring changes to wildlife health, and in particular to changes in fat composition.

This project has allowed us to gain a better understanding of what the nature of perspectives, attitudes, behaviour and knowledge on traditional and contemporary fats are in two distinct Arctic communities. Overall, a better understanding of perceptions of fats through this research project will help to address the needs of northern health and wildlife/environment professionals in promoting healthy food choices and of capturing early observations of Inuit experts (hunter and Elders) of possible shifts taking place in marine and terrestrial ecosystems associated with climate and other forms of environmental change.

\section{Fatty acids profiles, trends and sources}

Among the Inuit of Nunavik in 2004, all fatty acids including long chain polyunsaturated fatty acids (n-3 PUFAs) were measured from blood samples, particularly in both red cell membranes and in plasma. Levels of the major n-3 fatty acids, namely eicosapentanoic acid $(\mathrm{EPA})+$ docosahexanoic acid (DHA) increased with age. Levels among those over 40 years of age were about double of those under 40, and the later were about 4-5 times those of the general population of Québec. No differences based on sex were observed. On the other hand, trans-fatty acids were lower among older participants in comparison to the younger.

In terms of spatial trends, a north-south gradient is apparent, and is likely reflective of the availability and consumption of marine foods, whereby participants residing along the Ungava Bay and upper Hudson Bay coasts had higher n-3 PUFA concentrations and lower n-6:n-3 ratios, compared with those further to the south living along the Hudson Bay coast. The $n-6: n-3$ ratio is an indicator of consumption of foods of commercial versus marine origin. 
Comparison of results from the Nunavik health survey administered in 1992 with that from 2004 provides information on time trends. Analysis of fatty acids profiles for 1992 and 2004, found that n-3 PUFA in plasma went from about $10 \%$ in 1992 to about $7 \%$ of total fatty acids in 2004 (Table 1). These results also show an overall increase of n-6 PUFA concentrations over the period. The consequence is an increased n-6:n-3 ratio, considered a determinant of coronary heart disease. Moreover, these differences are maintained over different age groups whereby all age groups (18-29 years; 30-39 years; 40 years and over) saw a twofold n-6:n-3 ratio increase between 1992 and 2004 (Table 2).

The mean relative concentration of combined DPA (docosapentaenoic acid) + EPA + DHA accounted for more than $8.5 \%$ of total fatty acids. DPA is specific to seal blubber and thus, the quantity of DPA measured in cell membranes of survey participants is a signature of seal consumption.

Additional information on marine fatty acids and health can be found in the Electronic Supplemental Information 2. This material details recent research on fatty acids and blood pressure, heart rate variability, atherosclerosis and psychological distress. As well, information regarding gender specific determinants of dietary choice is provided in Supplemental Information 5.

\section{Infectious diseases challenges}

The legacy of the impact of infectious disease among Indigenous populations in North America is dark, with a history of massive death rates resulting in dramatic changes to population demographics seemingly overnight. Today, infectious disease still plays a significant role in terms of the overall burden of ill health among Indigenous peoples in the circumpolar region of Canada but to a much lesser extent than over the early part of the last century (Young and Bjerregaard 2008). Today's most important infectious agents of concern are those causing respiratory disease and those which are sexually transmitted. As well, links between infectious agents and cancer are emerging. Kelly et al. (2008) report liver and cervical cancer incidence rates among circumpolar Inuit as twice and three times higher respectively than among the US Caucasian populations (Fig. 2). Liver cancer is associated with Hepatitis B viral infection and cervical cancer with the Human Papillomavirus. The Helicobacter pylori bacterium is also suspected as a causal agent in the development of stomach cancer, another cancer which occurs more frequently among Circumpolar Inuit than among more southern Caucasians.

As well, zoonoses i.e. infectious agents present in wildlife and transmitted to humans, are particular to this geography given its people's intimate relationship with the land and its bounty. Water may also spread infectious agents either because of the type, or the lack of, drinking water treatment and distribution that is available in certain regions and/or because

Table 1 1992-2004 comparisons between relative mean concentrations of fatty acids (\% of total fatty acids $\pm \mathrm{SD}$ ) in plasma phospholipids expressed by age in Inuit of Nunavik

EPA eicosapentanoic acid; $D H A$ docosahexanoic acid; PUFA polyunsaturated fatty acids; SFA saturated fatty acids

\begin{tabular}{lrr}
\hline Fatty acids & \multicolumn{2}{l}{ All ages } \\
\cline { 2 - 3 } & $\begin{array}{l}1992(n=424) \\
\text { Mean } \pm \text { SD }\end{array}$ & $\begin{array}{l}2004(n=462) \\
\text { Mean } \pm \text { SD }\end{array}$ \\
\hline EPA+DHA & $8.57 \pm 4.47$ & $5.99 \pm 3.71$ \\
n-3 PUFA & $10.40 \pm 4.86$ & $7.38 \pm 4.02$ \\
n-6 PUFA & $21.60 \pm 4.80$ & $30.83 \pm 3.89$ \\
n6:n3 & $2.87 \pm 2.06$ & $5.78 \pm 3.84$ \\
SFA & $40.27 \pm 2.83$ & $43.84 \pm 1.78$ \\
\hline
\end{tabular}


Table 2 Relative mean concentrations of fatty acids (\% of total FA) in plasma phospholipids expressed by age groups (y) in Inuit of Nunavik: comparisons between 1992 and 2004

\begin{tabular}{|c|c|c|c|c|c|c|}
\hline \multirow[t]{2}{*}{ Fatty acids } & \multicolumn{2}{|l|}{$18-29 y$} & \multicolumn{2}{|l|}{$30-39 y$} & \multicolumn{2}{|l|}{${ }^{3} 40>y$} \\
\hline & $\begin{array}{l}1992 \\
(n=146)\end{array}$ & $\begin{array}{l}2004 \\
(n=177)\end{array}$ & $\begin{array}{l}1992 \\
(n=106)\end{array}$ & $\begin{array}{l}2004 \\
(n=120)\end{array}$ & $\begin{array}{l}1992 \\
(n=172)\end{array}$ & $\begin{array}{l}2004 \\
(n=165)\end{array}$ \\
\hline $\mathrm{EPA}+\mathrm{DHA}$ & $5.93 \pm 2.94$ & $4.43 \pm 2.73$ & $8.04 \pm 3.81$ & $5.06 \pm 2.27$ & $11.14 \pm 4.51$ & $8.35 \pm 4.25$ \\
\hline n-3 PUFA & $7.44 \pm 3.24$ & $5.64 \pm 3.02$ & $9.84 \pm 4.19$ & $6.47 \pm 2.46$ & $13.25 \pm 4.78$ & $9.90 \pm 4.58$ \\
\hline n-6 PUFA & $24.34 \pm 3.57$ & $32.52 \pm 2.95$ & $22.22 \pm 4.18$ & $31.79 \pm 2.74$ & $18.90 \pm 4.65$ & $28.31 \pm 4.20$ \\
\hline n6/n3 & $4.10 \pm 2.34$ & $7.57 \pm 4.45$ & $2.88 \pm 1.75$ & $5.89 \pm 3.04$ & $1.81 \pm 1.25$ & $3.77 \pm 2.44$ \\
\hline SFA & $39.63 \pm 2.83$ & $43.75 \pm 1.64$ & $40.18 \pm 2.67$ & $43.89 \pm 1.78$ & $40.88 \pm 2.82$ & $43.88 \pm 1.91$ \\
\hline
\end{tabular}

the practice of collecting untreated surface water for drinking is still fairly common (Martin et al. 2007).

Sedentary communities have challenges related to a dispersed population over a large geographic area which is isolated from major populated centres. Impressive population growth rates and a very young population, along with prohibitively high construction and maintenance-repair costs are among several global factors which set the scene for crowded and compromised living conditions that are ripe for the local propagation of infectious diseases. Other factors characteristic of the present Inuit society which are associated with increased frequency and severity of most infectious disease, and particularly with respiratory and sexually transmitted infections are very high smoking rates, including among adolescents, and a high prevalence of alcohol and drug consumption among adults and adolescents. Each of these contributing factors offers opportunity to alleviate the burden of disease.

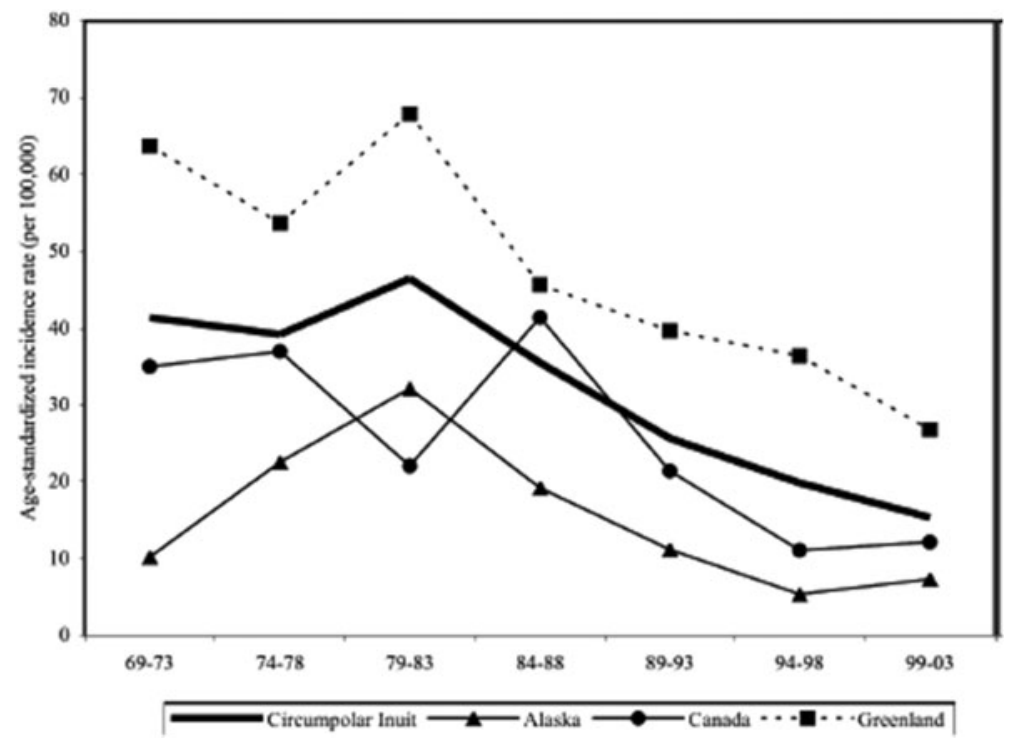

Fig. 2 Trend in incidence of cervical cancer among Inuit women, 1969-1973 to 1999-2003. Source: (Kelly et al. 2008) Note: Here "Canada" refers to NWT, Nunavut and Nunavik, and not Nunatsiavut, nor the Yukon 
Fortunately there are proven ways of managing infectious diseases given that their propagation is often manageable through immunization or the resulting disease often treatable with antibiotics for example. Such health services have infiltrated to various degrees into all Northern communities. Many northern immunization programs are in a state of relative infancy and their justification, introduction and evaluation are in part the subjects of investigation for IPY projects described below.

The health disparities between circumpolar Indigenous people, circumpolar nonIndigenous people, and more southern populations are fuelled in part by infectious disease and much remains to be learned about how these interact with the genetic, social and environmental fabric of the North. As well, there is potential for infectious disease to become more prominent in the future given the trend towards northern economic development - e.g. Plan Nord ${ }^{4}$ for the Quebec region — and of course, climate change.

Davidson et al. (2011) outline the major food and water-borne parasite issues facing the Arctic today. Climate change is having an impact on the health of wildlife that Inuit populations consume thereby having a direct impact on food security in two ways: first by modifying wildlife population numbers and secondly by providing the possibility of increasing human diseases acquired by eating infected meat or drinking infected water. Starting from the fact that both wildlife and parasite diversity in the Arctic is relatively low and therefore more vulnerable to perturbations, the Arctic ecosystem becomes more sensitive to wildlife invasions and environmental changes which in turn increases competition for food, alters timing and migration patterns and therefore sometimes introduces new pathogens. These changes in turn affect parasites by modifying their development and survival rates. A warmer environment can also alter the transmission of endemic parasites by expanding their range.

Parasites may invade more wildlife species or disease emergence and/or reduction may ensue. Climate change is also associated with retreating sea ice and rising river flows contributing to an expansion in marine shipping and tourism, both of which in their own right represent considerable risks in terms of introduction of novel species of parasites and their vectors. There is a role for the emerging Arctic tourism industry to play in educating their clients about potential food borne risks, particularly with respect to travel for tasting local foods. Unfortunately, baseline data for many wildlife species and their parasites are incomplete. Monitoring, parasite data baseline and acquiring sufficient environmental knowledge are needed to properly evaluate food safety risk in the Arctic.

Supplementary Electronic Material 3 provides further background information on infectious disease and research in the northern context.

\section{Respiratory disease among the young}

\subsection{IPY project: control of respiratory infections in Nunavik through immunization}

Nunavik is the northernmost health and social services region within the province of Quebec and for this reason Nunavik's population is at the forefront of immunization against respiratory infections among circumpolar nations. Of its approximately 10,000 inhabitants, $90 \%$ self identify as Inuit and live in 14 communities scattered along the coasts of the Ungava Bay, Hudson Strait and Hudson Bay.

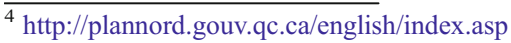


A study is underway evaluating the impact of a dual vaccination program and to study, for the first time, its effectiveness in preventing respiratory infections and otitis sequelae in a highly vulnerable population. The two vaccines are a pneumococcal conjugate vaccine (PCV-7) against seven strains of the pneumococcus bacteria and an influenza vaccine (trivalent inactivated) or seasonal flu vaccine. Both types of vaccines have been administered in various populations showing significant measures of efficacy but had not been systematically administered among Inuit populations. Moreover, there are no published data on the combined effect of the pneumococcal conjugate vaccine and the influenza vaccine for preventing respiratory infections and the complications and sequelae of otitis. There may be a synergistic effect knowing that viral infections can pave the way for secondary bacterial infections (Buchman and Brinson 2003; Rovers et al. 2004). As well, vaccinating a high proportion of children with both vaccines could result in a decrease in the circulation of pneumococcal and influenza strains in the community as a whole - or a group immunity effect-which could only increase the program's effectiveness. As such, the immunization program instituted in Nunavik constitutes a quasi-experiment.

The study involves the retrospective follow-up of surveillance and medical records over 12 birth cohorts of children up to the age of 5 , namely children born between 1994 and 2005. Among these 12 cohorts were three groups-those who received neither vaccine, some who did not receive the complete vaccination schedule and those who received the complete schedule of both vaccines. In Nunavik, audiology screening is a routine procedure at or around age 5 and combines audiometry, tympanometry and otoscopy. This program introduced in 1984 offers a unique opportunity to evaluate the impact of vaccination on audiological sequelae attributable to otitis media. Analysis are underway and results will inform on the effect of the immunization program on rates of respiratory disease, including otitus media, in the Nunavik population.

Preliminary results indicate however that while the vaccine is effective against the specific strains of pneumococcus in its make up, others strains tend to replace the target strains and it remains to be seen to what extent an overall significantly positive effect on the incidence rates of respiratory diseases will be achievable solely through immunization. The study will be completed in 2013.

Today, a 13-valent vaccine is administered providing more extensive coverage and immunization rates among infants and children are excellent. Furthermore, pneumococcal resistance to antibiotics seems low in the Nunavik population, despite the high prescription rate (Jetté 2004).

\section{Cervical cancer}

10.1 IPY project: the prevalence of human papillomavirus and its impact on cervical dysplasia in Northern Canada

This is the largest study of its kind in Canada. Data from Pap smear examinations from almost 15000 women living in the NWT, Nunavut, Labrador or the Yukon, HPV typing results, and demographic information were linked for analysis. The overall HPV infection rate of $25.8 \%$ among the women in the study is higher than for most countries (Clifford et al. 2005; Kitchener et al. 2006; Ronco et al. 2005), but is similar to Denmark (Kjaer et al. 2008) and the USA (Dunne et al. 2007) and lower than Mozambique (Castellsagué et al. 2001). 
There is no comparable rate available for Canada. In the sample, the infection rate among the Indigenous women was significantly higher than for non-Indigenous women $(31.6 \%$ versus $18.9 \%$ ) and the difference remained even after adjustment for the different age distributions among the two groups.

The prevalence rate among the Indigenous women in this study are similar to those found in studies among women of Nunavik (Hamlin-Douglas et al. 2010) and of Nunavut (Healey et al. 2001), which lends confidence to the claim that rates are higher among Inuit populations. All of these are lower than rates reported for some other cohorts such as for Mozambique, for example but are nonetheless among the highest rates in the world.

Rates for the non-Indigenous women in the cohort at $18.9 \%$ are higher than those reported for British Columbia (Moore et al. 2009) and Ontario women (Sellors et al. 2000 ) at $16.8 \%$ and $13.3 \%$ respectively. However it is not clear as to whether this represents a significant difference given limitations in directly comparing results. The larger range of HPV types included in this present study account in part for the higher rates reported.

The proportion of critical HPV types or those which are associated with cervical cancer, among HPV-positive women in the cohort is $78.6 \%$, regardless of ethnicity. This is considerably higher than the proportion found for the British Columbia (13.9\%) and Ontario $(9.6 \%)$ cohorts and more in line with the proportion reported for Nunavik $(70.6 \%)$. This presents an interesting finding as it suggests that women in the North, regardless of ethnicity, may be more at risk of infection with high risk types of the virus.

Similar to most European studies (Kjaer et al. 2008; Kulmala et al. 2007; Nielsen et al. 2008; Pannier-Stockman et al. 2008), the two most common HPV types detected in this study were HPV-16 and 31, two high risk types. HPV 16/18 is a measure of infection with either of the two types considered among the most high risk types for developing cancer (Muñoz et al. 2003). The HPV 16/18 prevalence in the NWT was relatively lower than that reported in all similar studies in Canada (Hamlin-Douglas et al. 2008; Moore et al. 2009; Sellors et al. 2000), but comparable to studies in Europe and the US (Dunne et al. 2007; Kitchener et al. 2006; Kjaer et al. 2008; Ronco et al. 2005). Several high risk HPV types other than HPV 16/18, such as HPV 39, 45, 51, 59 and 66 are relatively common in Northern Canada. Further analysis would be required to evaluate the efficacy of currently available vaccines against HPV in the northern context given that they target types 16, 18, 6 and 11.

The assessment of HPV overall prevalence, high risk prevalence, as well as prevalence of $16 / 18$ by age group showed higher prevalence in the younger age groups. While prevalence rates decline with age, the decline reaches it's lowest in the 40-49 year age group then reverses with age groups 50 and over experiencing increased infection rates. This U-shaped age-specific HPV prevalence distribution specific to the Indigenous group of the cohort has been observed in the Nunavik and Nunavut studies (Hamlin-Douglas et al. 2008; Healey et al. 2001; Moore et al. 2009; Sellors et al. 2000) as well as in Costa Rica (Herrero et al. 2005) and other Latin American countries (Franceschi et al. 2006). This differs from most of the European literature, which, with the exception of the former Soviet Union (Kulmala et al. 2007), reports a decreased prevalence after age 20 and a levelling off after age 45 (Franceschi et al. 2006; Kitchener et al. 2006; Kjaer et al. 2008; Ronco et al. 2005). Hamlin-Douglas et al. (2010) report that in Nunavik markers of sexual activity may explain this phenomenon. The IPY study group is currently exploring social and other lifestyle factors that may play an important role in explaining this distribution among the Indigenous population.

The relatively high prevalence of high risk HPV among this population especially among the Indigenous women will require further investigation to explore specific predictors of infection. This study supports continued education, awareness raising and promotion of the HPV vaccine with a special emphasis on the needs of northern Indigenous peoples. 
However, results also suggest that a new vaccine designed to target the profile of HPV infection typical of northern regions is to be considered.

\section{Hepatitis B virus}

11.1 IPY project: the viral hepatitis Northern network: a platform for addressing viral hepatitis in the Canadian North

The first objective was to develop an internet based software program that health care providers could access in order to learn of recent developments in the epidemiology, treatment and follow-up of HBV infected individuals and therefore diagnose/manage infections more effectively. CD-based versions of the program were distributed to nursing stations throughout the North followed by links to the web-site containing updated information.

The second objective was to determine why HBV in Canada's North appeared to result in cirrhosis and hepatocellular carcinomas less often than had been reported in the Indigenous populations of Alaska and Greenland (McMahon 2004). Here, paired serum samples (approximately 5 years apart) were obtained from HBV infected individuals from the three international regions. On analyses of the samples, it was discovered that HBV in Northern Canada underwent significantly more mutations over the 5 years of observation than was the case in Alaskan or Greenland specimens. This finding suggests that by mutating or changing its appearance, the "Canadian version" of the virus is able to evade detection by the patient's immune system and thereby, not elicit an inflammatory response that would eventually result in fibrosis, cirrhosis and perhaps, hepatocellular carcinoma (Solar et al. 2010).

The third objective of the study was to document the prevalence and outcome of occult HBV in additional areas of the North. To that end, over 600 stored blood samples from three communities in the Northwest Territories were tested by sensitive polymerase chain reaction technique and $4 \%$ were found to be HBV-DNA positive (i.e. occult infections). Although follow-up was limited to $40 \%$ of cases, no clinical, biochemical or radiologic evidence of cirrhosis or hepatocellular carcinoma were found in these individuals after a follow-up interval of approximately 25 years. Of note, only $1 / 7$ subjects with occult HBV at baseline (1984) remained HBV-DNA positive when retested in 2010. These findings suggest that occult HBV tends to have a benign course in Northern Canadians and persistent infection is uncommon.

The fourth and final objective of the study is underway. Here, the $400 \mathrm{HBV}$ positive and approximately 80 occult HBV infected individuals who were identified by testing the 198385 sera will be traced through administrative databases and vital statistics data to determine liver-related morbidity and mortality rates. Survivors in selected regions will be invited to participate in clinical, laboratory and radiologic assessments in an effort to grade and stage the extent of infection (and possibly need for treatment) at the present time.

In conclusion, HBV infection and exposure rates in Canada's North are estimated to be 5 to 20 times higher than in Southern Canada. Fortunately, the results of all studies to date suggest that the natural history of HBV in Canada's North is more benign than is the case in the majority of populations elsewhere in the world. Whether this finding reflects intrinsic differences in the virus or the host has yet to be determined. Preliminary data however, suggests the former. Presumably, the results from ongoing IPY-sponsored research and new initiatives will provide answers to these and other important questions regarding HBV in the Canadian North. 


\section{Zoonotic diseases and the safety of country foods}

12.1 IPY project: engaging communities in the monitoring of zoonotic diseases in traditional foods for food safety concerns

Two new laboratories, one in Nain, Nunatsiavut and the other in Yellowknife, NWT, were created and equipped with basic equipment for diagnostic testing. The Nunavik Research Center in Kuujjuaq was upgraded and personnel trained for basic bacteriology testing. Northern residents were hired and trained to perform diagnostic tests and to prepare sampling kits for hunters, who in turn were trained to collect samples from animals.

Once operational, these new facilities and personnel enabled the study of the following zoonotic agents of interest for northern Canada: Trichinella nativa, Toxoplasma gondii, Anisakidae nematodes, E. coli 0157:H7 and Salmonella spp. Diagnostic tests for Toxoplasma gondii, E. coli 0157:H7 and Salmonella spp. were developed or adapted and underwent preliminary validation for Canadian northern conditions. A secure data-entry website and interface was developed featuring the ability to add, modify, search, export and delete IPY specimen data, which will be stored in the latest version of the Canadian Cooperative Wildlife Health Centre database at the University of Saskatchewan and the IPY Polar Data Center. Only preliminary results are presented below, further analyses are still being conducted.

Supplementary Electronic Material 4 contains background information and details on the current knowledge status for major zoonotic species including Trichinella native, Toxoplasma gondii, Anisakidae nematodes and E. coli 0157:H7 and Salmonella.

These results represent a first step toward the creation of a database on the prevalence of these pathogens in traditional meats. Already, sharing of these samples with other scientists interested in studying other non-pathogenic bacteria and zoonotic protozoans have generated some results to add to this database (Lamhoujeb et al. 2012). Although there have been some advances on zoonotic diseases in the Canadian Arctic within the last 5 years, there is still a lot to do. Constant monitoring of zoonotic and wildlife diseases that will help create baseline data on all diseases is urgently needed. Without this information, differentiating between what is an emerging or re-emerging disease is impossible and food safety risk assessment analyses cannot be produced. Data is particularly missing on viruses and bacteria. Understanding the ecology of these diseases in the Arctic is essential for the development of proper and culturally adapted prevention measures. This information is necessary especially since the new Nutrition North Canada programme (http://www.nutritionnorthcanada.ca/poapr/index-eng.asp) is promoting consumption of country food and subsidizing the transportation of commercialized country food. These products are not systematically being tested for zoonotic parasites.

In response to the latest research on contaminant levels in Inuit populations, coupled with trans-fat, and n-3 research, public health authorities are promoting the consumption of some wildlife species more than others to alleviate contaminant levels and to increase the consumption of good fats. The equivalent knowledge for each zoonotic disease across the Canadian Arctic is lacking, therefore there is a potential that if overlooked by the public health policy makers, some zoonotic infections could increase.

\section{Knowledge translation into action}

Although the projects described herein are ongoing with their full impact expected to unfold over the next few months and years, new knowledge is already being produced to inform 
public health and frame actions with the intent to address health status inequality for Inuit in Canada. We give three examples on how the knowledge generated through research has influenced public health policies in the Arctic.

\subsection{The Nunavut food security task force}

The Nunavut Inuit Child Health Survey has been highly successful. The findings of the child health survey has resulted in a Nunavut food security task force, a federal call for proposals for early-age obesity intervention/prevention, and territorial nutritionists indicate that the findings (which are shared with them in a timely and pre-published format) are being heavily relied upon for public health decision making and in setting priorities for nutritional health interventions. From a population health perspective, the preschooler survey identified nutritional characteristics which, if persisting throughout life would theoretically result in greater risk of obesity and diet-related chronic diseases. The results indicate the importance of early life interventions and health promotion strategies to protect Inuit Health and to prevent an epidemiologic transition toward greater chronic disease risk.

\subsection{Elimination of trans-fats in Nunavik}

Results from the Urqsuk research project have directly affected nutritional policy at the public health level in Nunavik. Public Health senior management are integrating knowledge from this research into efforts and programs to eliminate trans-fats importation and consumption (reducing fats with deleterious effects), as well as promoting the consumption of traditional foods with beneficial n-3 fatty acids. Pregnant women may be a targeted subpopulation in the near term.

Following Denmark and Greenland which successfully reached minimum trans-fatty acids (TFA) levels through a strict regulation adopted in 2003, Makivik Corporation called the Nunavik Regional Board of Health and Social Services and Inuit organisations for a ban of TFA in June 2007. The Urqsuk project brought scientific and technical support in the practical implementation of the ban, by assessing the feasibility of a ban, initiating a strong public/private partnership, and involving a Southern undergraduate student and an Inuk high school student in a research project. (Counil et al. 2011)

\subsection{Safety and wild food consumption}

In Nunavik, since 1996, there is a Nunavik Trichinellosis Prevention Program, where the diagnosis is done at the Nunavik Research Centre in Kuujjuuaq, gives a $24 \mathrm{~h}$ Trichinella diagnostic service to all Nunavik communities that harvest walrus. Public health recommendations are given to the community majors who are in charge of communicating the information to their community members. This program is a collaboration between the Nunavik Regional Department of Public Health, the Hunter Support from the Kativik Regional Government, the municipalities and Makivik Corporation.

Prior to 2011, the Trichinella diagnostic test was only available for walrus but now tests can be done on other Arctic wildlife such as bear species. Furthermore, training is available upon request from the Canadian Food Inspection Agency in Saskatoon. Trichinellosis in the Arctic can be avoided if prevention programs are in place. A similar program is also available and organized by the Nunavut Health and Social Services. A list of necessary equipment needed has been established for other laboratories that would want to provide these diagnostic services. 


\section{Conclusions}

Thanks to public health surveillance systems we are able to follow trends in health indicators for populations within Inuit Nunangat. Their messages can be potent and should influence research priorities. The trend over time for life expectancy at birth for the population of Inuit Nunangat is increasing. This increase however, is not as marked as that for the whole of Canada. The population health indicators presented in section two tell us that overall there are no clear signs that the gap in health status between Inuit Nunangat and Canada is narrowing.

People living in Inuit Nunangat can expect to live a decade less than people living elsewhere in Canada. Three groups of people experiencing excess mortality in comparison with the rest of Canada are young men, post-menopausal women, and infants less than 1 year of age. Focussing research on understanding the determinants of injuries, both self-inflicted and non-intentional, on chronic diseases, particularly cancers, cardiovascular diseases and respiratory diseases; and on causes of mortality during the first year of life, the health inequality gap with respect to life expectancy at birth could more easily be reduced.

The people of Inuit Nunangat who have self-declared as having Inuit ancestry, are the youngest population in Canada. The number of newborns and young men among them therefore is relatively high, while the number of postmenopausal women is relatively low. This demographic profile has far reaching implications on many levels for Inuit society and identification and consideration of these implications will be essential for undertaking research that is pertinent and for the translation of research into action to support a healthy society. Results from the Inuit Health Survey identify that the basic necessities of food and housing stand out as critical indicators of poverty facing Inuit families today. These are in part artefact of the demographic boom in northern Indigenous communities.

Food insecurity levels are tremendously high across the North, particularly in Nunavut. Moreover, research is showing that the transition away from traditional foods towards market foods is degrading nutritional profiles. These two phenomena together represent risk of profound consequences on nutrition and therefore on a plethora of health endpoints. For example, the replacement of n-3 fatty acids abundant in many traditional foods, with transfatty acids, found in many market foods, represents not just a nutritional loss, but a nutritional deficit. The health benefits associated with $n-3 \mathrm{~s}$ are replaced with a disease promoting agent. While no epidemic in diet and obesity has been declared for Inuit Nunangat, its avoidance weighs in the balance of the adoption of short and medium term actions such as the ban on trans-fats that is now underway in Nunavik. Perhaps more than any other age group, children may be more vulnerable to this dual burden of disease over the long term and represent the largest demographic within Inuit society in Canada today. Furthermore, providing services and knowledge which enable the safe consumption of country foods in terms of zoonotic infections among all members of Inuit society becomes highly valuable. Such services are developing as significant knowledge gaps are filled and infrastructure and capacity are developed.

Research is also unveiling new physiological benefits of consuming traditional foods, particularly that from marine mammals. The Urqsuk project has looked at marine fats to uncover that they are probably involved in the protection of metabolic disorders generally associated with obesity (high triglycerides, low HDL-cholesterol, high blood pressure, etc.). They also are also important in the maintenance of high cardiac variability. Finally, but not least, given the profile of causes of mortality among the population of Inuit Nunangat, these n-3 fatty acids appear to offer some protection against mental health disorders. Both chronic diseases and self-inflicted 
injuries are identified through surveillance data as leading causes of death in a population experiencing excess mortality in comparison with that of Canada.

Considering the importance of mental health and suicide and, the increase, especially among women of chronic diseases, nutritional policies taking into account the demography and the state of natural resources should be implemented to restore the consumption of natural fats from the land and the sea. Such a policy should also discourage the importation and consumption of foods containing bad fats.

In terms of infectious disease, the burden of acute respiratory disease, particularly among the young, remains a significant public health issue. Immunization programs in human populations are a long-term undertaking requiring intensive resources and ongoing support for such initiatives is warranted. In addition to immunization, everything from hand washing to crowding must be considered in strategizing to lower the short and long term burden of this disease. For example, hearing deficits may contribute to lowering overall educational attainment, in itself a major determinant of health for any population.

Both the human papilloma virus and Hepatitis B virus are complex infectious agents each with a natural history that is particular to the northern Arctic context. IPY research has contributed to understanding their natural history and directly informs both primary health and public health actions to be taken to best prevent and address these diseases.

The IPY projects described herein address all of the sub-populations within Inuit Nunangat identified as being most at risk from facing premature death and many of the principal outcomes attributed as causing mortality. Progress has been made, and further work remains. Future assessment work should include morbidity data, as well as information on the perception of health status, to provide a fuller evaluation of population health status with which to inform the planning of future research priorities.

Northern inhabitants living outside of Inuit Nunangat also benefit from the IPY research, such as in the prevention of infection with the human papilloma virus and potential cancer risk.

Acknowledgements Special thanks go to both Dr. François Proulx and Dr. Mylène Riva for their valuable comments.

Open Access This article is distributed under the terms of the Creative Commons Attribution Noncommercial License which permits any use, distribution, and reproduction in any medium, provided the original author(s) and the source are credited.

\section{References}

Aboriginal Affairs and Northern Development Canada (2011) Government of Canada Program for International Polar Year: Highlights and Achievements, Ottawa ON

Anctil M (2008) Les faits saillants de l'enquête. Enquête de santé auprès des Inuits du Nunavik 2004. Qanuippitaa? Comment allonsnous? (pp 13). Québec: Institut national de santé publique du Québec (INSPQ) et Régie régionale de santé et des services sociaux du Nunavik (RRSSSN)

Bersamin A, Luick BR, King IB, Stern JS, Zidenberg-Cherr S (2008) Westernizing diets influence fat intake, red blood cell fatty acid composition, and health in remote Alaskan Native communities in the center for Alaska Native health study. J Am Diet Assoc 108(2):266-273

Bjerregaard P (2011) Inuit health in transition-Greenland survey 2005-2010. Population sample and survey methods SIF Writings on Greenland. National Institute of Public Health, Copenhagen

Bjerregaard P, Young TK, Dewailly E, Ebbesson SO (2004) Indigenous health in the Arctic: an overview of the circumpolar Inuit population. Scand J Public Health 32(5):390-395

Buchman CA, Brinson GM (2003) Viral otitis media. Curr Allergy Asthma Rep 3(4):335-340 
Castellsagué X, Menéndez C, Loscertales MP, Kornegay JR, dos Santos F et al (2001) Human papillomavirus genotypes in rural Mozambique. Lancet 358(9291):1429-1430

Chateau-Degat M-L, Dewailly E, Poirier P, Gingras S, Egeland GM (2008) Comparison of diagnostic criteria of the metabolic syndrome in 3 ethnic groups of Canada. Metabolism 57(11):1526-1532

Chateau-Degat M-L, Dewailly E, Louchini R, Counil E, Noël M et al (2010) Cardiovascular burden and related risk factors among Nunavik (Quebec) Inuit: insights from baseline findings in the circumpolar Inuit health in transition cohort study. Can J Cardiol 26(6):190-196

Clifford GM, Gallus S, Herrero R, Muñoz N, Snijders PJF et al (2005) Worldwide distribution of human papillomavirus types in cytologically normal women in the International Agency for Research on Cancer HPV prevalence surveys: a pooled analysis. Lancet 366(9490):991-998

Counil É, Gauthier M-J, Dewailly É (2011) Alimentation et santé publique dans les communautés des Inuit du Nord du Québec: vers un changement de paradigme? In: Petit J-G, Viger YB, Aatami P, Iserhoff A (eds) Les Inuit et les Cris du Nord du Québec. Presses de l'Université du Québec, Québec

Counil É, Gauthier MJ, Blouin V, Grey M, Angiyou E et al. (2012). Translational research to reduce trans-fat intakes in Northern Québec (Nunavik) Inuit communities: a success-story? International Journal of Circumpolar Health

Davidson R, Simard M, Kutz SJ, Kapel CMO, Hammes IS et al (2011) Arctic parasitology: why should we care? Trends Parasitol 27(6):238-244

Dewailly E, Blanchet C, Lemieux S, Sauvé L, Gingras S et al (2001) n-3 Fatty acids and cardiovascular disease risk factors among the Inuit of Nunavik. Am J Clin Nutr 74(4):464-473

Dunne EF, Unger ER, Sternberg M, McQuillan G, Swan DC et al (2007) Prevalence of HPV infection among females in the United States. JAMA: J Am Med Assoc 297(8):813-819

Ebbesson SO, Schraer CD, Risica PM, Adler AI, Ebbesson L et al (1998) Diabetes and impaired glucose tolerance in three Alaskan Eskimo populations. The Alaska-Siberia Project. Diabetes Care 21(4):563-569

Egeland GM, Faraj N, Osborne G (2010a) Cultural, socioeconomic, and health indicators among Inuit preschoolers: Nunavut Inuit Child Health Survey, 2007-2008. Rural Rem Health 10(2):1365

Egeland GM, Pacey A, Cao Z, Sobol I (2010b) Food insecurity among Inuit preschoolers: Nunavut Inuit Child Health Survey, 2007-2008. CMAJ: Canadian Medical Association Journal = Journal De L'association Medicale Canadienne 182(3):243-248

Egeland GM, Cao Z, Young TK (2011a) Hypertriglyceridemic-waist phenotype and glucose intolerance among Canadian Inuit: the International Polar Year Inuit Health Survey for Adults 2007-2008. CMAJ: Canadian Medical Association Journal = Journal De L'association Medicale Canadienne 183(9):E553E558

Egeland GM, Johnson-Down L, Cao ZR, Sheikh N, Weiler H (2011b) Food insecurity and nutrition transition combine to affect nutrient intakes in canadian arctic communities. J Nutr 141(9):1746-1753

El Hayek J, Egeland G, Weiler H (2010) Vitamin D status of Inuit preschoolers reflects season and vitamin D intake. J Nutr 140(10):1839-1845

Ferrazzano GF, Cantile T, Quarto M, Ingenito A, Chianese L et al (2008) Protective effect of yogurt extract on dental enamel demineralization in vitro. Aust Dent J 53(4):314-319

Franceschi S, Herrero R, Clifford GM, Snijders PJF, Arslan A et al (2006) Variations in the age-specific curves of human papillomavirus prevalence in women worldwide. International Journal Of Cancer Journal International Du Cancer 119(11):2677-2684

Galloway T, Young TK, Egeland GM (2010) Emerging obesity among preschool-aged Canadian Inuit children: results from the Nunavut Inuit Child Health Survey. International Journal Of Circumpolar Health 69(2):151-157

Hamlin-Douglas LK, Coutlée F, Roger M, Hanley J, Franco EL et al (2008) Prevalence and age distribution of human papillomavirus infection in a population of Inuit women in Nunavik, Quebec. Cancer Epidemiol Biomarkers Prev 17(11):3141-3149

Hamlin-Douglas LK, Coutlée F, Roger M, Hanley J, Franco EL et al (2010) Determinants of human papillomavirus infection among Inuit women of northern Quebec, Canada. Sex Transm Dis 37(6):377381

Healey SM, Aronson KJ, Mao Y, Schlecht NF, Mery LS et al (2001) Oncogenic human papillomavirus infection and cervical lesions in aboriginal women of Nunavut, Canada. Sex Transm Dis 28(12):694-700

Health Council of Canada (2011) Improving aboriginal maternal and child health in Canada: conversations about promising practices across Canada. Health Council of Canada, Toronto

Herrero R, Castle PE, Schiffman M, Bratti MC, Hildesheim A et al (2005) Epidemiologic profile of typespecific human papillomavirus infection and cervical neoplasia in Guanacaste, Costa Rica. J Infect Dis 191(11):1796-1807

Holben DH, Pheley AM (2006) Diabetes risk and obesity in food-insecure households in rural Appalachian Ohio. Preventing Chronic Disease 3(3):A82 
Howard BV, Devereux RB, Cole SA, Davidson M, Dyke B et al (2005) A genetic and epidemiologic study of cardiovascular disease in Alaska natives (GOCADAN): design and methods. International Journal of Circumpolar Health 64(3):206-221

Huet C, Rosol R, Egeland GM (2012) The prevalence of food insecurity is high and the diet quality poor in Inuit communities. J Nutr 142(3):541-547

Indian and Northern Affairs Canada (2009) Weekly cost of the revised Northern Food Basket for a family of four Retrieved March 29, 2010, from http:/www.ainc-ianc.gc.ca/nth/fon/fc/ch/cht0809-eng.asp

Kanatami IT (2011) Inuit in Canada. Inuit Tapiriit Kanatami, Ottawa

Jetté L (2004) Surveillance du pneumocoque-Rapport 2002. Institut National de Santé Publique du Québec, Québec

Johnson-Down L, Egeland GM (2010) Adequate nutrient intakes are associated with traditional food consumption in nunavut inuit children aged 3-5 years. J Nutr 140(7):1311-1316

Johnston KL, Thomas EL, Bell JD, Frost GS, Robertson MD (2010) Resistant starch improves insulin sensitivity in metabolic syndrome. Diabetic Medicine: A Journal Of The British Diabetic Association 27(4):391-397

Jørgensen ME, Bjerregaard P, Borch-Johnsen K (2002) Diabetes and impaired glucose tolerance among the inuit population of Greenland. Diabetes Care 25(10):1766-1771

Jørgensen ME, Glümer C, Bjerregaard P, Gyntelberg F, Jørgensen T et al (2003) Obesity and central fat pattern among Greenland Inuit and a general population of Denmark (Inter99): relationship to metabolic risk factors. Int J Obesity 27(12):1507-1515

Kahn HS, Valdez R (2003) Metabolic risks identified by the combination of enlarged waist and elevated triacylglycerol concentration. Am J Clin Nutr 78(5):928-934

Kelly J, Lanier A, Santos M, Healey S, Louchini R et al (2008) Cancer among the circumpolar Inuit, 19892003. II. Patterns and trends. Int J Circum Health 67(5):408-420

Kitchener HC, Almonte M, Wheeler P, Desai M, Gilham C et al (2006) HPV testing in routine cervical screening: cross sectional data from the ARTISTIC trial. Br J Cancer 95(1):56-61

Kjaer SK, Breugelmans G, Munk C, Junge J, Watson M et al (2008) Population-based prevalence, type- and age-specific distribution of HPV in women before introduction of an HPV-vaccination program in Denmark. Int J Cancer 123(8):1864-1870

Kovesi TA, Cao Z, Osborne G, Egeland GM (2011) Severe early lower respiratory tract infection is associated with subsequent respiratory morbidity in preschool Inuit children in Nunavut, Canada. J Asthma 48 (3):241-247

Kuhnlein HV, Receveur O, Soueida R, Egeland GM (2004) Arctic indigenous peoples experience the nutrition transition with changing dietary patterns and obesity. J Nutr 134(6):1447-1453

Kulmala S-MA, Shabalova IP, Petrovitchev N, Syrjänen KJ, Gyllensten UB et al (2007) Prevalence of the most common high-risk HPV genotypes among women in three new independent states of the former Soviet Union. J Med Virol 79(6):771-781

Lamhoujeb S, Banerjee S, Bin Kingombe C, Blais B, Dixon B et al. (2012) Testing for foodborne pathogens in Eastern Arctic food animals. Appl Environ Microb

Lemieux I, Poirier P, Bergeron J, Alméras N, Lamarche B et al (2007) Hypertriglyceridemic waist: a useful screening phenotype in preventive cardiology? Can J Card 23(Suppl B):23B-31B

Martin D, Bélanger D, Gosselin P, Brazeau J, Furgal C et al (2007) Drinking water and potential threats to human health in Nunavik: adaptation strategies under climate change conditions. Arctic 60(2):195-202

McMahon BJ (2004) Viral hepatitis in the Arctic. Int J Circum Health 63(Suppl 2):41-48

Minich K, Saudny H, Lennie C, Wood M, Williamson-Bathory L, Cao Z, Egeland GM (2011) Inuit housing and homelessness: results from the International Polay Year Inuit Health Survey 2007-2008. Int J Circumpolar Health 70(5):520-531

Moore RA, Richard A, Ogilvie G, Fornika D, Moravan V et al (2009) Prevalence and type distribution of human papillomavirus in 5,000 British Columbia women-implications for vaccination. Canc Causes Contr: CCC 20(8):1387-1396

Mouratoff GJ, Carroll NV, Scott EM (1967) Diabetes mellitus in Eskimos. J Am Med Assoc 199(13):107-112

Muñoz N, Bosch FX, de Sanjosé S, Herrero R, Castellsagué X et al (2003) Epidemiologic classification of human papillomavirus types associated with cervical cancer. N Eng J Med 348(6):518-527

Murphy NJ, Schraer CD, Bulkow LR, Boyko EJ, Lanier AP (1992) Diabetes mellitus in Alaskan Yup'ik Eskimos and Athabascan Indians after 25 year. Diabetes Care 15(10):1390-1392

Nielsen A, Kjaer SK, Munk C, Iftner T (2008) Type-specific HPV infection and multiple HPV types: prevalence and risk factor profile in nearly 12,000 younger and older Danish women. Sex Transm Dis 35(3):276-282

Nobmann ED, Byers T, Lanier AP, Hankin JH, Jackson MY (1992) The diet of Alaska Native adults: 19871988. Am J Clin Nutr 55(5):1024-1032 
Pacey A, Nancarrow T, Egeland GM (2010) Prevalence and risk factors for parental-reported oral health of Inuit preschoolers: Nunavut Inuit Child Health Survey, 2007-2008. Rural Remote Heal 10(2):1368

Pacey A, Weiler H, Egeland GM (2011) Low prevalence of iron-deficiency anaemia among Inuit preschool children: Nunavut Inuit Child Health Survey, 2007-2008. Public Health Nutr 14(8):1415-1423. doi:10.1017/s1368980010002429

Pannier-Stockman C, Segard C, Bennamar S, Gondry J, Boulanger JC et al (2008) Prevalence of HPV genotypes determined by PCR and DNA sequencing in cervical specimens from French women with or without abnormalities. J Clin Virol 42(4):353-360

Parkinson AJ (2008) The International Polar Year, 2007-2008, an opportunity to focus on infectious diseases in Arctic regions. Emerg Infec Dis 14(1):1-3

Pars T, Osler M, Bjerregaard P (2001) Contemporary use of traditional food among Greenlandic Inuit. Arctic 54(1):22-31

Ronco G, Ghisetti V, Segnan N, Snijders PJF, Gillio-Tos A et al (2005) Prevalence of human papillomavirus infection in women in Turin, Italy. Eur J Cancer (Oxford, England: 1990) 41(2):297-305

Rosol R, Huet C, Wood M, Lennie C, Osborne G, Egeland GM (2011) Prevalence of affirmative responses to questions of food insecurity: International Polar Year Inuit Health Survey, 2007-2008. Int J Circumpolar Health 70(5):488-497

Rovers MM, Schilder AG, Zielhuis GA, Rosenfeld RM (2004) Otitis media. Lancet 363(9407):465-473

Sagild U, Littauer J, Jespersen CS, Andersen S (1966) Epidemiological studies in Greenland 1962-1964. I. Diabetes mellitus in Eskimos. Acta Med Scand 179(1):29-39

Seligman HK, Bindman AB, Vittinghoff E, Kanaya AM, Kushel MB (2007) Food insecurity is associated with diabetes mellitus: results from the National Health Examination and Nutrition Examination Survey (NHANES) 1999-2002. J Gen Intern Med 22(7):1018-1023

Seligman HK, Laraia BA, Kushel MB (2010) Food insecurity is associated with chronic disease among lowincome NHANES participants. J Nutr 140(2):304-310

Sellors JW, Mahony JB, Kaczorowski J, Lytwyn A, Bangura H et al (2000) Prevalence and predictors of human papillomavirus infection in women in Ontario, Canada. Survey of HPV in Ontario Women (SHOW) Group. CMAJ 163(5):503-508

Solar K, Minuk GY, Borresen ML, Koch A, McMahon BJ et al (2010) Association between hepatitis B virus longitudinal genetic variability and clinical outcome in circumpolar indigenous populations (Abstract 1385). Hepatology 52(Suppl 4):987A

Sun Q, Ma J, Campos H, Hankinson SE, Manson JE, Stampfer MJ et al (2007) A prospective study of trans fatty acids in erythrocytes and risk of coronary heart disease. Circulation 115(14):1858-1865

Sun Q, Spiegelman D, van Dam RM, Holmes MD, Malik VS et al (2010) White rice, brown rice, and risk of type 2 diabetes in US men and women. Arch Intern Med 170(11):961-969

Vozoris NT, Tarasuk VS (2003) Household food insufficiency is associated with poorer health. J Nutr 133 (1):120-126

Willett WC (2006) Trans fatty acids and cardiovascular disease-epidemiological data. Atheroscler Suppl 7 (2):5-8

Young TK, Bjerregaard P (eds) (2008) Health transitions in Arctic populations. University of Toronto Press, Toronto

Young TK, Bjerregaard P, Dewailly E, Risica PM, Jørgensen ME et al (2007) Prevalence of obesity and its metabolic correlates among the circumpolar inuit in 3 countries. Am J Public Health 97(4):691-695

Zhang X, Rahemtulla F, Zhang P, Beck P, Thomas HF (2009) Different enamel and dentin mineralization observed in VDR deficient mouse model. Arch Oral Biol 54(4):299-305

Zhou YE, Kubow S, Egeland GM (2011) Highly unsaturated n-3 fatty acids status of Canadian Inuit: International Polar Year Inuit Health Survey, 2007-2008. Int J Circumpolar Health 70(5):498-510 